\title{
Pragmatic Transfer in Iraqi EFL Learners' Refusals
}

\author{
Ahmed Qadoury Abed \\ Department of Translation, Faculty of Arts, The University of Al-Mustansiriyah, Baghdad, Iraq \\ E-mail: ahmed_121204@yahoo.com
}

Received: March 26, 2011 Accepted: April 26, $2011 \quad$ doi:10.5539/ijel.v1n2p166

\begin{abstract}
The present study deals with pragmatic transfer of Iraqi EFL learners' refusal strategies as reflected by their responses to a modified version of 12- items written discourse completion task; and compare with two groups ,namely Iraqi native speakers of Arabic and American native speakers of English. The task consisted of three requests, three offers, three suggestions, and three invitations. Each one of these situations included one refusal to a person of higher status, one to a person of equal status, and one to a person of lower status. Data analyzed according to frequency types of refusal strategies and interlocutor's social status. It is found that the frequency of use of refusals by Iraqi EFL learners is different from that of Americans, though they do share some similarities. Iraqi EFL learners are apt to express refusals with care and/or caution represented by using more statements of reason/explanation, statements of regret, wish and refusal adjuncts in their refusals than Americans. Americans are more sensitive to their interlocutor's higher and equal status, whereas Iraqi EFL learners to lower status. Evidences proved the existence of little difference between IEFL males and females in refusal frequency and refusal adjuncts.
\end{abstract}

Keywords: Refusal strategies, Pragmatic transfer, Discourse Completion Task (DCT), Iraqi EF learners

\section{Introduction}

Much of the work in interlanguage pragmatics has been conducted within the framework of speech acts. Speech acts can be thought of as 'functions' of language, such as complaining, thanking, apologizing, refusing, requesting, and inviting. Within this view, the minimal unit of communication is the performance of linguistic act. All languages have a means of performing speech acts and presumably speech acts themselves are universals, yet the 'form' used in specific speech acts varies from culture to culture. Thus, the study of second language speech acts is concerned with the linguistic possibilities available in languages for speech act realization and the effect of cross-cultural differences on second language performance and on the interpretation by native speakers of second language speech acts (Wolfson, 1989:183).

Numerous studies in interlanguage pragmatics have recognized that the learners' ability to use appropriate speech acts in a given speech act event and to use appropriate linguistic forms to realize this speech act is a main component of pragmatic competence. Fraser (1983:30) describes pragmatic competence as "the knowledge of how an addressee determines what a speaker is saying and recognizes intended illocutionary force conveyed through subtle attitudes". Rintell (1997:98) also pointed out that "pragmatics is the study of speech acts", arguing that L2 learner pragmatic ability is reflected in how learners produce utterances in the target language to communicate specific intentions and conversely, how they interpret the intentions which their utterances convey. One of the consistent findings in the empirical studies of speech act behaviour is that, although the typology of speech acts appears to be universal, their conceptualization and verbalization can vary to a great extent across cultures and languages. In other words, L2 learners may have access to the same range of speech acts and realization strategies as do native speakers, but they can differ from in the strategies that they choose. Therefore, it is clear that L2 learners must be aware of L2 socio-cultural constraints on speech acts in order to be pragmatically competent. When second language learners engage in conversations with native speakers, difficulties may arise due to their lack of mastery of the conversational norms involved in the production of speech acts. Such conversational difficulties may in turn cause breakdowns in interethnic communication (ibid.). When the native speakers violate speech acts realization patterns typically used by native speakers of a target language, they often suffer the perennial risk of inadvertently violating conversational and politeness norms thereby forfeiting their claims to being treated by their interactants as social equals (Kasper, 1990:203ff). Communication difficulties are resulted when conversationalists do not share the same knowledge of the subtle rules governing conversations. Scarcella (1990) ascribes high frequency of such difficulties to the fact that "non-native speakers, when conversing, often transfer the conversational rules of their first language into the second" (p. 338). Refusals are also of interest due to their typically complex constructions. They are often 
negotiated over several turns and involve some degree of indirectness. In addition to this, their form and content tends to vary depending on the type of speech act that elicits them (request, offer, etc.), and they usually vary in degree of directness depending on the status of the participants (see Beebe et al., (1990: 56) and Byon (2003:249)).

To the researcher's best knowledge , there is no an existing study dealing with pragmatic transfer of Iraqi EFL learners' refusals to requests, invitations, orders, and suggestions. For this reason, the present study aims to fill up this gap by investigating pragmatic transfer in Iraqi EFL learners' performances of the face-threatening act of refusal with status equal, and status unequal (a person of lower status talking to someone of higher status and a person of higher status talking to someone of lower status). The primary purpose is to present data describing this transfer as their responses to DCT are compared with those of Iraqi Arabic native speakers (those who only use Arabic) and American native speakers of English. This comparison will be done by examining the differences in refusal strategies (or semantic formulas) and status perspective. Also, it is to raise the pragmatic and pedagogical awareness of Iraqi professors, who currently focus only on grammatical and/or structural/semantic aspects of the language.

\section{Pragmatic Transfer}

The use of rules of speaking from one's speech act community when interacting or when speaking in a second or a foreign language is known as pragmatic transfer. Weinreich (1953) says" (as cited in Wolfson, 1989):

Those instances of deviation from the norms of either language which occur in the speech act of bilinguals as a result of their familiarity with more than one language, i.e. as a result of language contact, will be referred to as interference phenomena. It is these phenomena of speech, and their impact on the norms of either language exposed to contact, that invite the interest of the linguist (p.141).

What L2 learners must know for successful speech act performance has been presented in a "top-down processing" manner (Kasper, 1984):

Learners first have to recognize the extra-linguistic, cultural constraints that operate in a NS's choice of a particular speech act appropriate to the context. They also have to know how to realize this speech act at the linguistic level, and in accordance with L2 socio-cultural norms (p.3).

Cohen (1996:254) terms this "Socio-cultural knowledge" as

... speakers ability to determine whether it is acceptable to perform the speech act at all in the given situation and, so far, to select one or more semantic formulas that would be appropriate in the realization of the given speech act.

Transfer occurs in two ways :(1) negative transfer or 'interference' occurs where the two languages do not share the same language system, resulting in production of errors; and (2)positive transfer or 'facilitation', where the two languages share the same language system and the target form is correctly transferred(see Brown:2007:102ff). Pragmatic error or failure, as stated by Phuong (2006:13), occurs where speech act strategies are inappropriately transferred from L1 to L2. Since Arabic and English are not the same in language system, thus, cross-cultural study like the present one focuses on negative transfer because this is a source of misleading or miscommunication. The cross-cultural study of speech acts is vital to the understanding of international communication. It is realized that face-threatening acts are particularly important to study because they are the source of so many cross-cultural miscommunications. Research has been done on a number of face-threatening speech acts, for example, on apologies, requests, complaints, and disagreement. The evidence provided in these studies suggests that second-language learners are faced with the great risk of offending their interlocutors or of miscommunication when performing face-threatening acts. While grammatical error may reveal a speaker to a less proficient language-user, pragmatic failure reflects badly on him/her as a person.

The problem in such situations is often due to differences between languages in the social rules of speaking. It is thus due to the L2 learner's lack of pragmatic competence in the target language, resulting in what Phuong (ibid.) calls "pragmatic failure." Leech (1983) also points out that "transfer of the norms of one community to another may well lead to 'pragmatic failure' and to the judgment that the speaker is in some way being impolite" (p.281). In performing face-threatening acts, therefore, speakers must integrate personal and societal values with linguistic competence and, most importantly, gain some knowledge of "face-work") and some experience using it in L2 interaction.

As Leech (ibid.) demonstrates, there exist universal strategies in performing face-threatening acts. At the same time we are also aware of cross-cultural differences in the realization of speech acts. People may transfer some culturally specific politeness strategies from native language into the target language. They may accurately or 
inaccurately perceive linguistic differences between their native language and the target language. Even if they accurately perceive differences, however, they may have difficulty producing the differences accurately, or they exaggerate them.

\section{Literature Review}

The relevant literature for refusals is very rich, particularly in intra-cultural communication. Studies are of three orientations: those related to one particular language, as done by Japanese or Chinese linguists, or those related to foreign language compared with American/British/Australian English, or those related to Arabic and American English (see Phuong, 2006:18-25). Beebe, et al. (1990) compared the refusals given by native speakers of Japanese and native speakers of English by using a DCT of 12 items. The classification used in the present study and all other studies before are Beebe, et al's. They found great differences between Americans and Japanese in the order, frequency, and content of semantic formulas in refusals. Each adopted a different strategy for refusals; Japaneses based on the social status of interlocutors while Americans on the degree of familiarity or the social distance from the interlocutors. Saeki and O'keef (1994) studied American and Japanese refusals by using an experimental design. Participants responded to a scenario, like a candidate looking for a job, by writing what they would say to the person in the situation. Liao and Brenham (1996) employed a six-item written DCT to compare American English and Mandarin Chinese refusal strategies. Their analysis revealed that Americans used more strategies than Chinese in making refusals. Phuong (2006) worked on a cross-cultural pragmatic analysis of refusals to requests by Australian native speakers and Vietnamese learners of English. Results proved Australian refusals are different from those of Vietnamese, though they do share some similarities. Parallel to the differences in culture, Americans and Vietnamese also differed in the way they say "No" to their conversational partners. Vietnamese were apt to express refusals with caution and/or care. Americans, on the other hand, were more direct in the way they refuse, especially when they employed more "No" phrases.

The relevant literature of Arabic ESL/EFL learners ' refusals is not as rich as other cultures or nations. Some of these studies were done by Arab linguists or co-authored with natives, or by natives. Stevens (1993), cited in Phuong (2006:20), studied Arabic and English refusals using a written DCT. His DCT consisted of 15 situations, eight requests and seven invitations. His findings are similar to Beebe, et al, revealing that refusals involved multiple strategies and that interlocutors seldom refuse outright, i.e. L2 learners used inappropriate strategies. Hussein (1995), cited in Nelson et.al. (2002;43), discussed making refusals in Arabic as part of a larger study of speech acts in Arabic. He lists some of the strategies used by Arabic native speakers in refusals and maintains that indirect refusals are used with acquaintance of equal status, and with other close friends of unequal status. His study is descriptive in nature and is based on examples, which he gathered by means of participant observation. Al-Shawali (1997) investigated the semantic formulas used by Saudi and American male undergraduate students performing refusals. The results revealed, as mentioned in Al-Kahtani (2005:36ff), that Saudis and Americans used similar semantic formulas in refusing request, invitation, offer, and suggestion. The study also proved that there were no significant differences between them except in the employment of the direct 'no'. Al- Issa (1998), in a study of Jordanian Arabic refusals, found by using a DCT that Jordanians were more likely to express regret (like "I'm sorry") than Americans, and that both groups employed explanations and reasons more than any other strategies. It was found that there were three areas in which socio-cultural transfer is existent in EFL learners' speech: choice of selecting semantic formulas, length of responses, and content of semantic formulas. Each was found to reflect cultural values transferred from Arabic to English. Nelson, et al (2002), in a DCT study, found that Egyptians and Americans differ in the level of directness used in face-to-face communication; both groups employed similar strategies when making refusals; and many were used with equal degree of frequency. Al-Kahtani (2005) found that there were differences in the way Saudis and Americans realized the speech act of refusal with respect to the three dimensions of semantic formulas: the order, frequency, and content of semantic formulas. The two groups were not different across all situations. There were instances in which they tended to react to the same way as in 'request'. Al-Eryani (2007), in a DCT study, found out that although a similar range of refusal strategies were available to Americans and Yemenis, cross-cultural variation was evident in the frequency and content of semantic formulas used by each language group in relation to the contextual variables. Yemenis tended to be less direct in their refusals by offering preceding "reason" or "explanation" other than their own desire in refusing. Americans, on the other hand, used different semantic order by preceding "regret" in the first position giving more direct refusals. Abdul Sattar et. al. (2011) attempted to outline the preferred semantic formulas used in refusing suggestions in Arabic Iraqis living in Malaysia. They found that Iraqis employed some preferred types of refusal indirect patterns when refusing a suggestion. They tended to use "No" followed by explanation. This might indicate that they tend to be rude and risk of losing other's face when using negative ability and willingness. The researchers stated that their refusals were always mitigated and justified by giving reasons, explanations and other indirect strategies like using openers (or semantic adjuncts) to define the relationships, apologies, etc. 


\section{Refusal Strategies}

\subsection{The Speech Act of Refusal}

Refusals, as all the other speech acts, occur in all languages. However, not all languages/ cultures refuse in the same way nor do they feel comfortable refusing the same invitation or suggestion. The speech act of refusal occur when a speaker directly or indirectly says 'no' to request or invitation. Refusal is a face-threatening act to the listener/ requester/ inviter, because it contradicts his or her expectations, and is often realized through indirect strategies. Thus, it requires a high level of pragmatic competence. Cohen (1996:258f) used semantic formula to analyze speech act sets of refusal (refusing requests, invitations, offers and suggestions), and concluded that direct refusal as "NO" was not a common strategy for any of the subjects, regardless of their language background. For example, an expression of regret, common in Americans' refusals, was generally produced by the Chinese speakers, which might lead to unpleasant feelings between speakers in an American context.

Speakers who may be considered fluent in a second language due to their mastery of the grammar and vocabulary of that language may still lack pragmatic competence; in other words, they may still be unable to produce language that is socially and culturally appropriate. In cross-cultural communication, refusals are known as 'striking points' for many non-native speakers (Beebe, et al, 1990). Refusals can be tricky speech acts to perform linguistically and psychologically since the possibility of offending the interlocutor is inherent in the act itself (Know, 2004). As a face-threatening act, a sensitive pragmatic task and high pragmatic competence concern constructing refusals. As a failure to refuse appropriately can risk the interpersonal relations of the speakers, refusals usually include various strategies to avoid offending one's interlocutors. However, the choice of these strategies may vary across languages and cultures. For example, in refusing invitations, offers and suggestions, gratitude was regularly expressed by American English speakers, but rarely by Egyptian Arabic speakers (see Nelson, et. al., 1996; and Nelson, et. al., 2002). When Mandarian Chinese speakers wanted to refuse requests, they expressed positive opinion (e.g., 'I would like to....') much less frequently than American English ,since Chinese informants were concerned that if they ever expressed positive opinions, they would be forced to comply.

\subsection{Classification of Refusal Strategies}

Beebe et al. (1990:55-73) classified Refusals into two categories [Note 1]. The shaded symbols are done by the researcher for the purpose of classification and analysis:

\section{Direct}

1. Using performative verbs (I refuse) Ii

2. Non performative statement Iii

- "No"

○ Negative willingness/ability (I can't./I won't./I don't think so)

II. Indirect

1. Statement of regret (I'm sorry.../I feel terrible...) III

2. Wish (I wish I could help you...) IIii

3. Excuse, reason, explanation (My children will be home that night./I have a headache) IIiii

4. Statement of alternative IIiv

- I can do X instead of Y (I'd rather.../I'd prefer...)

- Why don't you do X instead of Y (Why don't you ask someone else?)

5. Set condition for future or past acceptance (If you had asked me earlier, I would have...) IIv

6. Promise of future acceptance (I'll do it next time./I promise I'll.../Next time I'll...) IIvi

7. Statement of principle (I never do business with friends.) IIvii

8. Statement of philosophy (One can't be too careful.) IIviii

9. Attempt to dissuade interlocutor IIix

- Threat or statement of negative consequences to the requester (I won't be any fun tonight to refuse an invitation)

- Guilt trip (waitress to customers who want to sit a while: I can't make a living off people who just order coffee.)

- Criticize the request/requester (statement of negative feeling or opinion; insult/attack (Who do you think you are?/That's a terrible idea!) 
- Request for help, empathy, and assistance by dropping or holding the request

- Let interlocutor off the hook (Don't worry about it./That's okay./You don't have to.)

- Self-defense (I'm trying my best./I'm doing all I can do.)

10. Acceptance that functions as a refusal IIx

○ Unspecific or indefinite reply

- Lack of enthusiasm

11. Avoidance IIxi

$\circ$ Nonverbal

- Silence

- Hesitation

- Doing nothing

- Physical departure

- Verbal

- Topic switch

- Joke

- Repetition of part of request (Monday?)

- Postponement (I'll think about it.)

- Hedge (Gee, I don't know./I'm not sure.

They also added that these refusals may be preceded by adjuncts like:

1. Statement of positive opinion/feeling or agreement (That's a good idea.../I'd love to...) Ai

2. Statement of empathy (I realize you are in a difficult situation.) Aii

3. Pause fillers (uhh/well/oh/uhm) Aiii

4. Gratitude/appreciation Aiv

Refusals can be seen as a series of the following sequences:

1. Pre-refusal strategies: these strategies prepare the addressee for an upcoming refusal .

2. Main refusal (Head Act): this strategy expresses the main refusal.

3. Post-refusal strategies: these strategies follow the head act and tend to emphasize, justify, mitigate, or conclude the refusal response.

For instance, a refusal example below shows an instance of a refusal sequence to a boss' request for an employee to stay at work two extra hours:

\begin{tabular}{|c|c|c|c|}
\hline \multirow[t]{2}{*}{ Boss: } & \multicolumn{3}{|c|}{ I was wondering if you might be able to stay a bit late this evening, say, until about 9:00 pm or so. } \\
\hline & Response & Refusal-sequences & $\sim$ Strategy \\
\hline \multirow[t]{5}{*}{ Employee } & Uh, I'd really like to & [PRE-REFUSAL] & $\sim$ Willingness \\
\hline & but I can't & {$[\mathrm{HEAD}$ ACT $]$} & $\sim$ Direct refusal \\
\hline & I'm sorry & [POST-REFUSAL] & $\sim$ Apology/Regret \\
\hline & I have plans & [POST-REFUSAL] & $\sim$ Reason/Explanation \\
\hline & I really can't stay & [POST-REFUSAL] & $\sim$ Direct refusal \\
\hline
\end{tabular}

\section{The Written Discourse Completion Task}

The written Discourse Completion Task (or WDCT) consists of twelve situations [Note 2]. It was divided into four categories: refusals to (1) requests, (2) invitations, (3) offers, and (4) suggestions. In each case, the task was designed so that one refusal will be made to someone of higher status, lower status, or a status equal. The responses of the three groups will be compared to each other to find out to what extent the Iraqi University-level students of English manipulate their pragmatic competence of the target language to refuse in English. This 
12-items WDCT is a form of questionnaire depicting some natural situations to which the respondents are expected to respond making refusals. This test was originally designed by Beebe, et al (1990) and has been widely used since then in collecting data on speech acts realization both within and across language groups. The questionnaire used in this investigation involves 12 written situations. They were divided into four groups: three requests(items $\# 1, \# 2$, and $\# 12$ ), three invitations (items $\# 3$, \#10, and \#4), three offers( items $\# 8$, $\# 5$, and $\# 6$ ), and three suggestions (items \#7, \#9, and \#11). Each situation includes one refusal to a person of higher status, one to a person of equal status, and one to a person of lower status (see Appendix for the complete WDCT). Requests are defined as polite demands for something; the requester asks a favour of the other person as to borrow class notes. Invitations are types of requests as to come to dinner. Instead of asking a favour, the inviter is usually attempting to be thoughtful and kind. Offers refer to asking individuals if they want something as a piece of cake. Suggestions are ideas put forward for people to consider as lecturing less in class.

\subsection{Administration of the Test}

The WDCT is administered to fifty-five participants, distributed into three groups: (1) 30 Iraqi EFL learners (henceforth IEFL)(15 males and 15 females) represented by Iraqi university-level students of English as a second language in the Department of Translation, Faculty of Arts, Al-Mustansiriyah University (the WDCT held in 3/3/2009), (2) 15 Iraqi Arabic native speakers (henceforth INSA)(8 males and 7 females) [Note 3], and (3) 10 American native speakers of English (henceforth ANSE)( 6 males and 4 females). The first two groups are given enough time to complete the task. Immediate feedback (i.e., explanations and details) is given when needed. ANSEs answered by emails; majority of them took about three weeks to reply to the researcher's emails [Note 4]. The ages of INSA are between (25- 41), all have academic degrees, with at least three years experience in teaching or business careers. Their academic fields are Arabic, geography, engineering, history, computer programming, fine arts, law, and biology. The ages of ANSE are between (18-37) living in USA or Malaysia. Majority of them have academic degrees in English, engineering, and business administration. To ensure the accuracy of the Arabic and English version of the WDCT, the English modified version was translated into Arabic by the researcher himself, a native speaker of Arabic. Then, the Arabic version was assessed by four: two individuals fluent in Arabic (holding Ph D in Arabic) and the other two fluent in Arabic and English( holding Ph $\mathrm{D}$ in Translation). Finally, the Arabic version was back-translated into English by a professional translator. The existing drawbacks were resolved during the discussions between the researcher, the professional translator, and the two Arabic experts.

For validity, this WDCT has its face and content validity since it is used widely in relevant studies (see Phuong, 2006:46ff). The content validity of its Arabic translation is obtained by submitting the translation to three experts in translation. On their suggestions, some rewording was done.

\subsection{Research Questions}

This study investigates how IEFL learners and ANSEs will make refusals in particular situations. The research questions are:

1- Are IEFL learners are aware pragmatically of this speech act? That is, are there instances of pragmatic transfer?

2- Are IEFL learners and ANSE different in using refusal strategies and refusal adjuncts?

3- Are IEFL males and females learners different in using refusal strategies and refusal adjuncts?

\subsection{Data Collection}

To obtain an adequate set of strategies, frequencies, and semantic formulas, the researcher first divided the subjects' replies into sets of idea units (see Nelson et. al., 2002:46). For the Iraqi Arabic data, a professional translator was asked to translate them into English ones. Both the English and Arabic data were then classified according to strategies suggested by Beebe et. al. (1990)(see sect. 4.2 above). For example, if a participant refused an invitation to a friend's house for lunch or party, like the one in situation no. 4 (see Appendix below), saying "I'm sorry, I already have plans. Maybe next time". this was coded as:

I'm sorry, I already have plans. Maybe next time.

IIi IIiii IIvi

Or

No, thanks now that I'm on a diet.

Iii Aiv IIiii

Or like the responses of two INSA, as follows: 


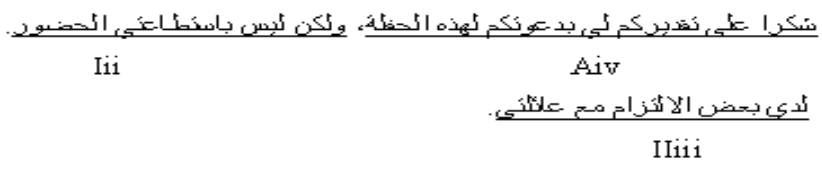

Or

$$
\text { IIvi }
$$

The researcher consulted the two Arabic experts when some replies were not within Beebe et. al's classification. Examples of these are those related to colloquial Iraqi. The codes suggested by the researcher to these strategies were finally specified to all replies. The total number of semantic formulas of any kind used for each situation was obtained for each of the three subject groups. Then, the frequency of each formula for each situation is counted and listed.

\section{Results}

Results are analyzed according to the frequency of strategies, semantic formulas, interlocutor's social status, and refusal adjuncts. For IEFL, gender will be added as a variable to get a better understanding of males and females' communication towards this speech act.

\subsection{Refusal strategies: A comparison}

In order to compare the frequency of strategies used by INSA, IEFL, and ANSE, the number of each strategy is counted. Tables $(1,2$, and 3 below) present a detailed description of these refusal strategies used. Gender is used as a variable only for IEFL. The total number of refusal strategies used by the three groups is (1171): (659) are used by male and female IEFLs, (216) by ANSEs, and (269) by INSAs. The percentages mentioned in all tables are those related to each group. That is, percentages for IEFL are found by dividing the number of use of each strategy on the total number of all strategies. This will reflect the individualism of each group. Basic statistics and Windows Excel 2003 are used for gathering and analyzing data.

IEFL males used (341) refusal strategies at (\%51.74) while (318) refusal strategies were for females at (\%48.26). IEFLs used (225) direct refusal strategies at (\% 34.22) while (434) for indirect strategies at (\% 65.78); ANSEs used (37) direct strategies at (\%17.06), and (179) were indirect strategies at (\% 82.94); and INSAs used only (25) direct strategies at $(\%$ 8.44) while (271) strategies are indirect at $(\% 91.56)$. These numbers and percentages indicate clearly that the three groups adopted indirect strategies more than direct ones. This in turn indicates a similarity between them even the percentages of indirect strategies are relatively different. The strategy of "reason/explanation" was in the first position in INSAs (\% 39.93) and ANSEs (\%23.26).On the other hand , "non-performative statements" was in the first position for IEFLs (\%34.22).Avoidance as a refusal strategy was the less used one in INSAs (\% 1.01) and ANSEs (\%1.85). No single instance was registered for avoidance and verbal refusing strategies in IEFLs. Examples of these direct strategies" using performative verbs" used by INSAs are the following.

$$
\begin{aligned}
& \text { - أنا أرخضن هذا الطيلب ' }
\end{aligned}
$$

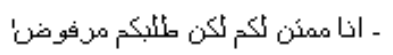

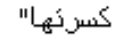

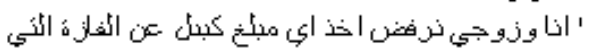

No instance of direct strategies is registered in the other two groups, which clearly reflects insights of existing pragmatic transfer. Table (4) below is a comparison of these refusal strategies used by the three groups. Numbers of instances, percentages and high-low ranks are mentioned. IEFLs did not use the following refusal strategies: "using performative verbs", "statement of principle", "acceptance as a refusal", "avoidance", and "verbal". INSAs did not use two refusal strategies, namely, "condition for future acceptance" and "acceptance as a refusal". ANSEs did not use the following two strategies: "using performative verbs" and "verbal". This clearly indicates a relative similarity between IEFLs and ANSEs in avoiding certain refusal strategies; an instance of change in IEFLs' use and knowledge occurred leading indirectly to state again that some insights of positive pragmatic transfer are evident. Positive pragmatic transfer, to the understanding of the researcher, is represented in using and also avoiding these refusal strategies.Another instances of positive transfer is the use of "regret" refusal strategy occurring in the third position in all the three groups. Furthermore, as an instance of negative transfer, is the extensive use of "wish" refusal strategy by IEFLs where (28) instances at (\% 4.24), particularly in the fourth position of the used strategies. On the other hand, (4) instances were found for INSAs and ANSEs at (\% 1.35$)$ and (\% 1.85), particularly in the eighth and tenth positions, respectively. The other instance to be examined here is the use of "statement of principle" by IEFLs only. To the researcher's best understanding, the reason behind is 
less acquaintance with such structures or strategy in English. Examples of these uses by ANSEs and INSAs are the following:

- I never do these things with mates.

- I never like such things.

- Never tell these things again.

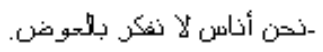

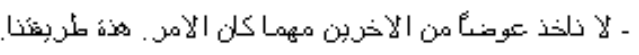

$$
\begin{aligned}
& \text { - لبنس هذا من سلوكنا و مبائنا. }
\end{aligned}
$$

\subsection{Semantic formulas}

The semantic formulas of the three groups are outlined in Tables $(5,6,7$, and 8 below) with reference to interlocutor's social status. In all situations and social status, the use of the strategy of "Reason/Explanation" is inevitable. The minimum use of semantic formulas is seen in Request where majority of the subjects' replies contained two formulas. The maximum use is in Offer. Majority of the subjects prefer to use "Non- performative statement" refusal strategy in the first position of the semantic formulas for the four speech acts, followed by "Reason/Explanation" or "Attempt to dissuade the interlocutor". Also, an important point here is that if the reply begins with a refusal adjunct, the semantic formula will start by "Non-performative statement", especially for Request, while, on the other hand, different refusal strategies for the other three speech acts. Instances of pragmatic transfer have been seen in the entire three interlocutor's social statuses. These instances of pragmatic transfer are stated when both IEFLs and ANSEs adopt similar refusal strategies and sometimes similar refusal adjuncts. Majority of the patterns of semantic formulas contain two or three refusal strategies. Only six instances were with four strategies. In Request, all the three groups used three patterns for lower and equal interlocutor's low and equal status, while four patterns were for higher status. This indicates that all the three groups are more sensitive to higher status than other two statuses. In Invitation, ANSEs used less number of patterns of refusal strategies than the other two groups, especially for lower and equal statuses. IEFLs used more patterns than others, especially in lower and equal statuses. In Suggestion, the behaviour of the three groups was about to be similar since all used more than four patterns of refusal strategies in the three interlocutor's social statuses. In Offer, IEFLs used more patterns than INSAs and ANSEs since they used more than five patterns of refusal strategies for the three interlocutor's social statuses. INSAs used fewer patterns than the other two groups.

\subsection{Refusal Adjuncts}

The results of using refusal adjuncts are stated in Table (9) below. The total number of used refusal adjuncts by the three groups is (421): INSAs used (170) instances at (\%40.38) of the total number of adjuncts, IEFLs used (169) instances at (\%40.14), and ANSEs used (82) instances at (19.48). The numbers and percentages indicate a clear approximation between INSAs and IEFLs, compared with the third group. This extensive use of refusal adjuncts is coincided with higher interlocutor's social status (items \#12, \#4, \#6, and \#11) where (189) instances at (\%44.89) of the total number of adjuncts. To the researcher's best knowledge, these refusal adjuncts are used as decreasing factors of refusing. The maximum use of these adjuncts for ANSEs is (13) instances for (item \#3/ invitation /lower status). While the maximum is (27) instances for INSAs and IEFLs in (item \#11/offer/ higher status). Also, it can be said that the differences in using refusal adjuncts is related to culture variance between Iraqis and Americans. For example, ANSE don't need to give or express feelings when they are refusing others. Like to what's stated in Nelson, et. al. (2000:52), this is also related to the nature of the language and method of communication. Arabic users of English still tend to adopt their native tendencies in such real life situations. The most common adjunct are "thank you, thanks, I thank you", or similar statements. The following table will also prove this fact since the total number of the fourth type of refusal adjuncts, namely, "Gratitude /appreciation" is (91) with percentage of $(\% 53.84)$.

The use of refusal adjuncts by IEFL males and females is in table (10) below. The results show that females used more refusal adjuncts than males. The females used (86) instances at (\%50.88) of the total number of adjuncts used by IEFLs whereas (83) instances at (\%49.12) for males. This indicates no such a big difference between males and females. But gender is still seen reflecting the fact that IEFL females are less direct in refusing, instead preferring to start replies by adjuncts. No instance of "statement of empathy" refusal adjunct is registered by both males and females. The maximum use is seen in "gratitude/appreciation" refusal adjunct. Males used (53) instances at (\%31.36) of the total number of IEFLs' adjuncts, whereas (38) instances at (\%22.48) for females. Seventy eight instances coincided with interlocutor's higher status in both, (58) instances for equal status, and (33) instances for lower status. This clearly indicates that both males and females have similar reactions towards interlocutor's social status, especially higher one. This is used a strategy for decreasing the effects of refusing. Request is the less speech act in using refusal adjuncts where only (21) instances were registered. The maximum use is in Offer where (57) instance found. Forty four instance were found for Invitation, and (47) for Suggestion. 


\subsection{Interlocutors" Social Status}

Table (11) below is a comparison among the three groups of participants in this WDCT with references to interlocutor's social status. (395) instances were registered for interlocutor's lower status at (\%33.73) of the total number of refusal strategies, (392) instances for equal status at (\%33.47), and (384) at (\%32.79).In the three interlocutor's social statuses, IEFLs used more strategies than the other two groups. ANSEs are the least which in turn indicates that ANSEs are more sensitive, especially to higher and equal status since they make fewer refusals compared with higher status. On the other hand, IEFL are only sensitive to lower status. This can be justified to cultural differences between Arabic and English societies.

\section{Discussion}

The present study investigates pragmatic transfer in Iraqi EFL learners' performances of the face-threatening act of refusal with three interlocutor's social statuses: lower, equal, and higher. Therefore, three research questions put forwards. The first research question was: "Are IEFL learners are aware pragmatically of this speech act? That is, are there instances of pragmatic transfer?" The results of the present study proved that IEFL were capable of refusing these twelve situations. Moreover, they were apt to identify the possible refusal strategies, semantic formulas, and refusal adjuncts. They were able to use (659) instances at (\%56.27) of the total number of refusal strategies (1171). These instances were nine of these fourteen stated strategies in Beebe, et al. (1990). "Non-performative statements" was the most used refusal strategy while "Using performative verbs", "Statement of principle", "Acceptance as a refusal", "Avoidance/silence", and "verbal" were out of use. Tables (5, 6,7, and 8 ) presented these patterns of semantic formulas and refusal adjuncts used by the three groups of participants. Many instances of positive pragmatic transfer were found. IEFLs adopted similar semantic strategies to ANSEs. The three groups used "Excuse/reason/ explanation" extensively since this strategy giges the possibility to reduce the effects of refusing. Also, the three groups used "Regret" in the third position. Another instance of pragmatic transfer is the negligence of one particular refusal strategy, namely, "Verbal", whereas one instance is registered for INSAs. Both IEFLs and ANSEs were able to adopt relatively similar patterns of semantic formulas and refusal adjuncts (especially for higher status). On the other hand, there were also instances of difference between the two groups, especially when both IEFLs and INSAs used similar refusal strategies for lower and equal statuses. All these justification can lead to say that Iraqi EF learners were pragmatically aware of refusals since many evidences of pragmatic transfer existed.

The second research question was: "Are IEFL learners and ANSE different in using refusal strategies and refusal adjuncts?" The results proved that even there were similarities between IEFLs and ANSEs , instances of difference were also found in frequency and content of refusal strategies. Both points of similarity and difference can be plainly regarded positive and negative transfer, respectively. One of the most evident differences between the two groups is related to interlocutor's social status. ANSEs were more sensitive to higher status while IEFLs (and INSAs) to lower and equal status.

The third research question was: "Are IEFL males and females learners different in using refusal strategies and refusal adjuncts?" The results presented in Tables (10 and 12) that both IEFL males and females behaved differently. IEFLs used (659) refusal strategies: IEFL males used (341) refusal strategies at (\%51.74) while (318) refusal strategies were for females at (\%48.26). Females were more sensitive to higher status than males, a matter totally related to the values of Iraqi culture and communication. This sensitivity was reflected in using more refusal adjuncts than males; females used (86) instances at $(\% 50.88)$ of the total number of adjuncts used by IEFLs whereas (83) instances at (\%49.12) for males. Therefore, evidences proved a slight difference between IEFL males and females.

\section{Conclusions}

Refusals of IEFL are different from those of ANSE and INSA, though they do share some similarities. Parallel to differences in culture, IEFL and ANSE also differ in the ways they say "NO" to their conversational partners. IEFL are at to express refusals with caution and/ or care, represented by using more "Statements of excuse /reason/ explanation", "Statements of regret", "Statements of wish", and refusal adjuncts (especially those of gratitude and appreciation like "thank you' and 'thanks') in their refusals than others. ANSE are more sensitive to interlocutor's social status in higher and equal, whereas IEFL are in lower status. This is also reflected in the higher percentage of "Non-performative statements" like 'can't' and 'don't agree', and 'no'. Instead, ANSE employ more "Statements of principles", "Statements of philosophy", "Statements of acceptance as a refusal", and "Avoidance", especially silence. IEFL still adopt their native -language tendencies when start refusing a situation. This is proved by their percentage of refusal adjuncts, which is about-to be- equal to INSA, and double the ANSE. IEFL males are more sensitive to interlocutor's social status in all four types of life situations; this can be justified by being more in communication and responsibilities than females. On the other hand, IEFL females use more refusal adjuncts than males, especially with offers. Consequently, IEFL are aware pragmatically of refusals; and results prove that there is a kind of positive pragmatic transfer represented by following the same order of 
semantic formulas (or refusal strategies) and refusal adjuncts adopted by ANSE. IEFL males used more refusal strategies than females, whereas females used more refusal adjuncts than males.

\section{References}

Abdul Sattar, Q, Salasiah, C. and Suleiman, R. (2010). A Study on strategies used in Iraqi Arabic to refuse suggestions. The International Journal of Language Society and Culture, 30, 81-95.

Al-Issa, A. (2003). Sociocultural transfer in L2 speech behaviours: evidence and motivating factors. International Journal of Intercultural Relations, 27, 581-601. doi:10.1016/S0147-1767(03)00055-5, http://dx.doi.org/10.1016/S0147-1767(03)00055-5

Al-Kahtani, S. (2005). Refusals realization in three different cultures: A speech act theoretically-based cross cultural study. Journal of King Saud University, 18, 35-57.

Beebe, L.M., Takahashi, T., \& Uliss-Weltz, R. (1990). Pragmatic transfer in ESL refusals, In: R. C. Scarcella, E. Anderson and S.D. Krashen (Eds.), On the Development communicative competence in a second language. Cambridge, MA: Newbury House Publishers. 55- 73.

Brown, H. D. (2007). Principles of Language Learning and Teaching ( $5^{\text {th }}$ ed.). London: Longman.

Brown, J. D. (2001). Pragmatic tests: Different purposes, different uses, In: K. R Rose and G. Kasper (Eds.), Pragmatics in Language Teaching. Cambridge: CUP, 301-325.

Byon, A. (2003). The Korean speech act of refusals: Sociopragmatic Analysis. The Sociolinguistic Journal of Korea, 11, 241-270.

Cohen, A. D. (1996). Developing the ability to perform speech acts. Studies in Second Language Acquisition, 18, 253-267. doi:10.1017/S027226310001490X, http://dx.doi.org/10.1017/S027226310001490X

Fraser, B. (1983). The Domain of Pragmatics, In: J. Richards and R. Schmidt (Eds.), Language and Communication. New York: Longman, 29-59.

Kasper, G. (1984). Pragmatic comprehension in learner-native speaker discourse. Language Learning, 34, 1-20. doi:10.1111/j.1467-1770.1984.tb00349.x, http://dx.doi.org/10.1111/j.1467-1770.1984.tb00349.x

Kasper, G. (1990). Linguistic politeness: current research issues. Journal of Pragmatics, 14, 193-218. doi:10.1016/0378-2166(90)90080-W, http://dx.doi.org/10.1016/0378-2166(90)90080-W

Kasper, G. \& Rose, K. R. (2001). Pragmatics in Language Teaching: An Introduction, in: K. Rose and G., Kasper(eds.), Pragmatics in Language Teaching. Cambridge:CUP, 1-9.

Known, J. (2004). Expressing Refusals in Korean and in American English. Multilingual, 23, 339- 364.

Nelson, G., Al-Battal, M and Echol, C. (1996). Arabic and English Complaint Responses: Potential for Pragmatic Failure. Applied Linguistics, 17, 411-432. doi:10.1093/applin/17.4.411, http://dx.doi.org/10.1093/applin/17.4.411

Nelson, G., Al-Battal, M and El-Bakary, W. (2002). Directness vs Indirectness: Egyptian Arabic and US English Communication Style. International Journal of Intercultural Relations, 26, 39-57. doi:10.1016/S0147-1767(01)00037-2, http://dx.doi.org/10.1016/S0147-1767(01)00037-2

Phuong, T. M. (2006). Cross-Cultural Pragmatics: Refusals of Requests by Australian Native Speakers of English and Vietnamese Learners of English. MA Dissertation, The University of. Queensland. Australia. [Online] Available: http://www.asian-efl-journal.com/ Thesis_Phuong.pdf. (July 20, 2009).

Richards, J. C. and Schmidt, R. (Eds.) (1983). Language and Communication. New York: Longman.

Rintell, E. (1997). Getting your speech act together: The pragmatic ability of second language Learners. Working Papers on Bilingualism, 17, 96-106.

Rose, K. R. and Kasper, G. (Eds.). (2001). Pragmatics in Language Teaching. Cambridge: CUP.

Sadler, R. W. (2004). A Case Study Examination of ESL Students in Freshmen English Composition. Unpublished Ph D Dissertation, University of Arizona. [Online] Available: http://www.eslweb.org/index.htm (March 28, 2009).

Scarcella, R.C. (1990). Communication Difficulties in Second Language Production, Development, and Instruction, in: Scarcella, E. Anderson and S.D. Krashen (Eds.), On the Development communicative competence in a second language. Cambridge, MA: Newbury House Publishers. 335-347.

Scarcella, R. C., Anderson E. S. and Krashen, S. D. (Eds.). (1990). On the Development communicative competence in a second language. Cambridge, MA: Newbury House Publishers.

Weinrinch,U. (1953). Language in Contact: Findings and Problems. New York: Linguistics Circle of New York. Wolfson, N. (1989). Perspectives, Sociolinguistics and TESOL. Boston: Heinle \& Heinle. 


\section{Notes}

Note 1. Please search the following website by CARLA for details about Beebe et al. (1990)http://www.carla.umn.edu/speechacts /refusals/index.html. This classification has been used by the succeeding works like Sadler, R. W. (2004) "A Case Study Examination of ESL Students in Freshmen English Composition", Unpublished Ph D Dissertation, University of Arizona , cited in: http://www.eslweb.org/index.htm. Also, see Kasper \& Rose (2001:1-9) for these languages in which this classification is taken into consideration, like French, Japanese, Chinese, German, Spanish, Turkish, and Hebrew.

Note 2. See Brown, J. D. (2001:301-325) for a detailed study of the used pragmatic tests in second language classroom.

Note 3. As Nelson et. al. (1996) and Nelson, et. al. (2002) did in their studies, the researcher himself translated the English version of the applied WDCT into Arabic, then submitted this translation to three experts in translation who gratefully assess this translation making the necessary modifications.

Note 4. The researcher is grateful to two persons who helped him in obtaing responses of ANSE. They are Agnieszka Alboszta ( American English Institue, Oregan University,USA /alboszta@uoregon.edu) and Masoud El-sherif (University Utara of Malaysia, Malaysia /elsharifmas@hotmail.com ).

Table 1. Male and Female IEFL Performance and Refusal Strategies

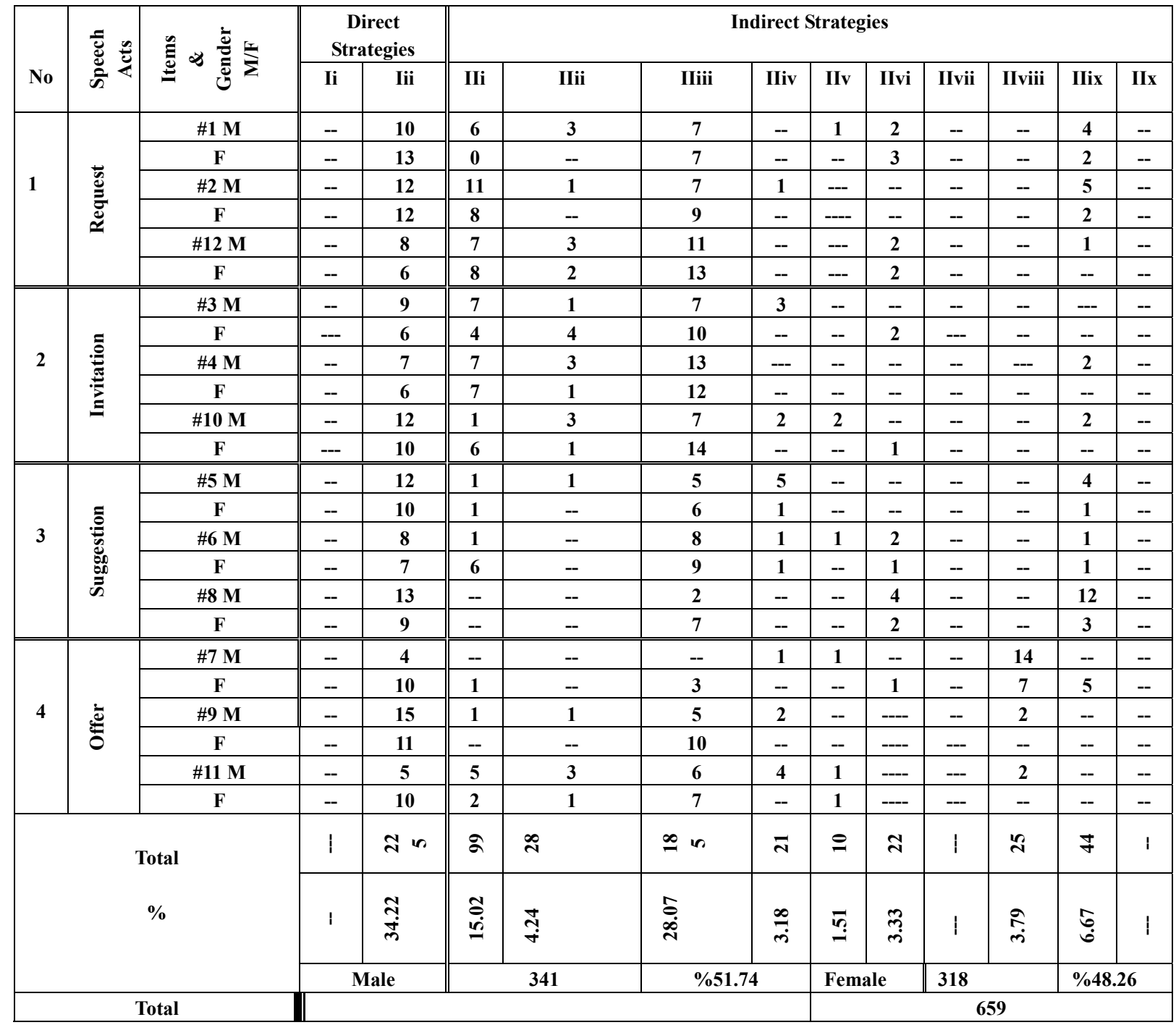


Table 2. ANSE Performance and Refusal Strategies

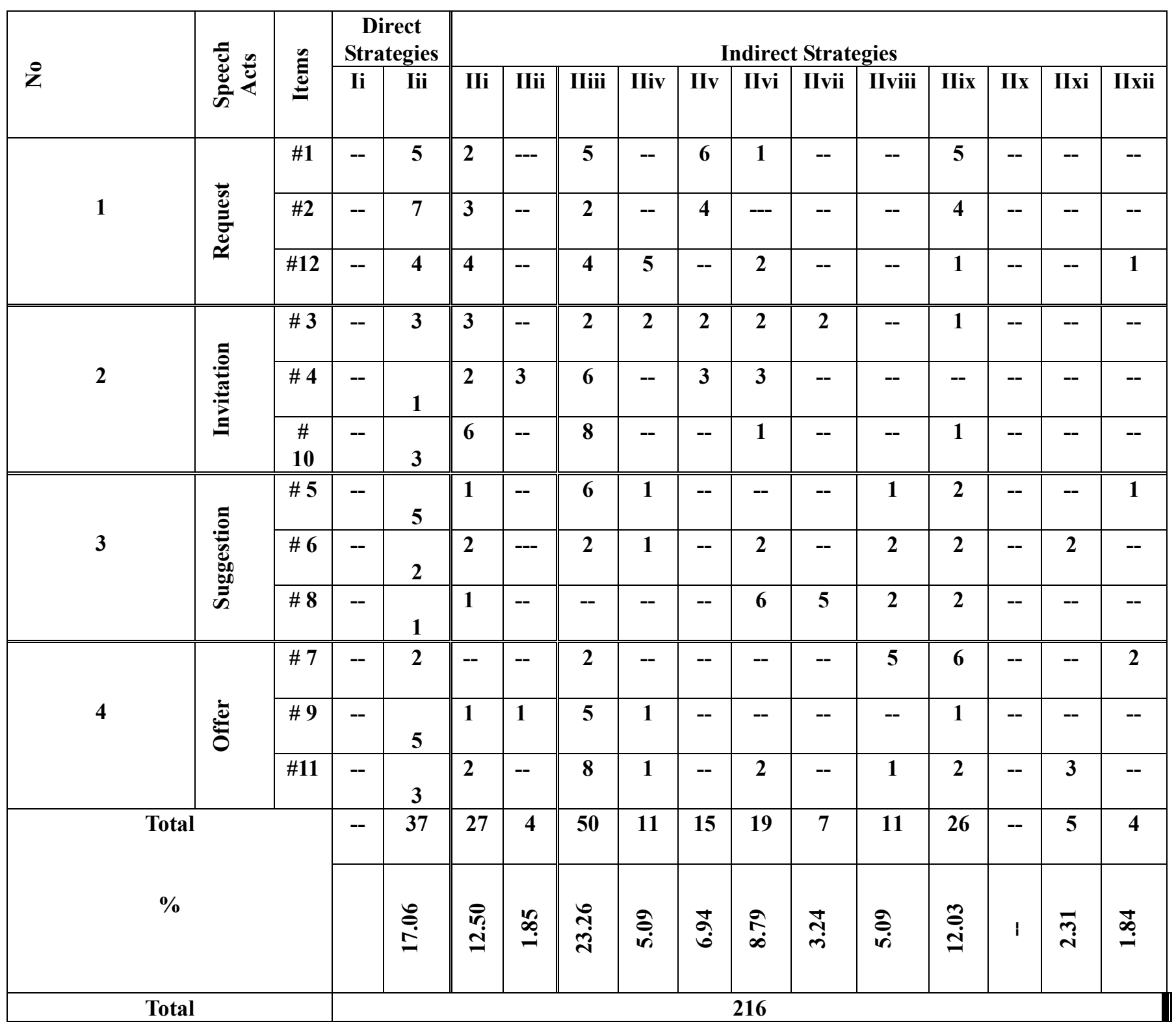


Table 3. INSA Performance and Refusal Strategies

\begin{tabular}{|c|c|c|c|c|c|c|c|c|c|c|c|c|c|c|c|c|}
\hline \multirow[b]{2}{*}{$\stackrel{0}{z}$} & \multirow{2}{*}{ 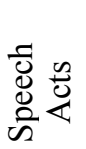 } & \multirow{2}{*}{ 氖 } & \multicolumn{2}{|c|}{ Direct Strategies } & \multicolumn{12}{|c|}{ Indirect Strategies } \\
\hline & & & $\mathrm{Ii}$ & Iii & III & IIIi & IIiii & IIiv & IIv & IIvi & IIvii & IIviii & IIix & IIx & IIxi & IIxii \\
\hline & \multirow{3}{*}{ 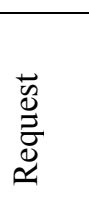 } & $\# 1$ & 1 & 6 & 6 & -- & 9 & 1 & -- & 3 & -- & -- & -- & -- & 1 & -- \\
\hline \multirow[t]{2}{*}{1} & & $\# 2$ & 1 & 8 & 5 & 2 & 8 & -- & -- & -- & -- & -- & -- & -- & -- & -- \\
\hline & & $\# 12$ & 1 & 4 & 7 & 1 & 12 & -- & -- & -- & 1 & -- & -- & -- & 1 & -- \\
\hline & \multirow{3}{*}{ 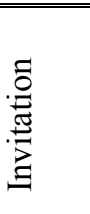 } & \#3 & 2 & 4 & 6 & -- & 13 & -- & -- & -- & -- & -- & -- & -- & -- & -- \\
\hline \multirow[t]{2}{*}{2} & & $\# 4$ & 1 & 4 & 6 & -- & 11 & -- & -- & 4 & -- & -- & -- & -- & 1 & -- \\
\hline & & $\# 10$ & 1 & 4 & 6 & 1 & 11 & -- & -- & 2 & -- & 1 & -- & -- & -- & -- \\
\hline \multirow{3}{*}{3} & \multirow{3}{*}{ 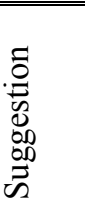 } & \#5 & 1 & 7 & 2 & -- & 12 & -- & -- & 1 & 1 & -- & -- & -- & -- & -- \\
\hline & & $\# 6$ & 1 & 6 & 4 & -- & 11 & -- & -- & -- & 1 & 1 & -- & -- & -- & -- \\
\hline & & $\# 8$ & 3 & 6 & 4 & -- & 8 & -- & -- & -- & 5 & -- & -- & -- & -- & -- \\
\hline \multirow{3}{*}{4} & \multirow{3}{*}{$\underbrace{\grave{0}}_{0}$} & $\# 7$ & 6 & 5 & -- & -- & 6 & -- & -- & -- & 3 & -- & 1 & -- & -- & 1 \\
\hline & & $\# 9$ & 4 & 7 & 4 & -- & 8 & -- & -- & -- & -- & 1 & -- & -- & -- & -- \\
\hline & & $\# 11$ & 3 & 3 & 3 & -- & 9 & -- & -- & -- & -- & 2 & -- & -- & -- & --- \\
\hline \multirow{2}{*}{\multicolumn{2}{|c|}{$\begin{array}{c}\text { Total } \\
\%\end{array}$}} & & $\approx$ & 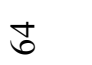 & $\tilde{n}$ & $\nabla$ & $\stackrel{\infty}{=}$ & - & $i$ & 으 & $=$ & $n$ & - & 1 & $n$ & - \\
\hline & & & $\underset{\infty}{\stackrel{J}{*}}$ & $\frac{\tilde{\sigma}}{\dot{\sim}}$ & $\stackrel{9}{\Im}$ & $\stackrel{n}{\dddot{n}}$ & ڤे & $\stackrel{\overbrace{}}{0}$ & 1 & $\hat{m}$ & $\vec{r}$ & $\stackrel{\infty}{\stackrel{\infty}{\longrightarrow}}$ & $\stackrel{m}{?}$ & 1 & ס्. & $\stackrel{m}{?}$ \\
\hline \multicolumn{3}{|c|}{ Total } & \\
\hline
\end{tabular}

Table 4. Refusal Strategies: A Comparison

\begin{tabular}{|l|l|l|c|c|c|c|c|c|c|c|c|}
\hline \multirow{2}{*}{ No } & \multicolumn{2}{|c|}{ Refusal Strategies } & \multicolumn{3}{c|}{ INSA } & \multicolumn{3}{c|}{ IEFL } & \multicolumn{3}{c|}{ ANSE } \\
\cline { 2 - 13 } & Strategy Name & $\begin{array}{l}\text { Symb } \\
\text { ol }\end{array}$ & no & $\%$ & rank & no & $\%$ & $\begin{array}{l}\text { ran } \\
\text { k }\end{array}$ & no & $\%$ & Rank \\
\hline 1 & $\begin{array}{l}\text { Using } \\
\text { Performative } \\
\text { verbs }\end{array}$ & Ii & 25 & 8.44 & 4 & -- & -- & -- & -- & -- & -- \\
\hline 2 & $\begin{array}{l}\text { Non-Performative } \\
\text { statements }\end{array}$ & Iii & 64 & 21.62 & 2 & $\begin{array}{c}22 \\
5\end{array}$ & 34.22 & 1 & 37 & 17.06 & 2 \\
\hline 3 & Regret & Iii & 53 & 17.90 & 3 & 99 & 15.02 & 3 & 27 & 12.50 & 3 \\
\hline 4 & Wish & Ilii & 4 & 1.35 & 8 & 28 & 4.24 & 5 & 4 & 1.85 & 10 \\
\hline 5 & $\begin{array}{l}\text { Reason/ } \\
\text { Explanation }\end{array}$ & Iiiii & 118 & 39.93 & 1 & 18 & 28.07 & 2 & 50 & 23.26 & 1 \\
\hline 6 & $\begin{array}{l}\text { Alternative } \\
5\end{array}$ & Iiiv & 1 & 0.33 & 10 & 21 & 3.18 & 8 & 11 & 5.09 & 7 \\
\hline 7 & $\begin{array}{l}\text { Condition for } \\
\text { future acceptance }\end{array}$ & Iiv & --- & --- & --- & 10 & 1.51 & 9 & 15 & 6.94 & 6 \\
\hline
\end{tabular}




\begin{tabular}{|c|c|c|c|c|c|c|c|c|c|c|c|}
\hline 8 & $\begin{array}{l}\text { Promise of future } \\
\text { acceptance }\end{array}$ & Iivi & 10 & 3.37 & 6 & 22 & 3.33 & 7 & 19 & 8.79 & 5 \\
\hline 9 & Principle & Iivii & 11 & 3.71 & 5 & --- & -- & -- & 7 & 3.24 & 8 \\
\hline$\overline{10}$ & Philosophy & Iiviii & 5 & 1.68 & 7 & 25 & 3.79 & 6 & 11 & 5.09 & 7 \\
\hline 11 & $\begin{array}{l}\text { Dissuade } \\
\text { interlocutor }\end{array}$ & Iiix & 1 & 0.33 & 10 & 44 & 6.67 & 4 & 26 & 12.03 & 4 \\
\hline 12 & $\begin{array}{l}\text { Acceptance as a } \\
\text { refusal }\end{array}$ & Iix & --- & --- & -- & --- & -- & -- & 5 & 2.31 & 9 \\
\hline 13 & $\begin{array}{l}\text { Avoidance/ } \\
\text { silence }\end{array}$ & Iixi & 3 & 1.01 & 9 & -- & -- & -- & 4 & 1.85 & 10 \\
\hline 14 & Verbal & Iixii & 1 & 0.33 & 10 & -- & -- & -- & --- & --- & -- \\
\hline \multirow{2}{*}{\multicolumn{3}{|c|}{ Total }} & \multicolumn{3}{|c|}{$\begin{array}{c}296 \\
(\% 25.27)\end{array}$} & \multicolumn{3}{|c|}{$\begin{array}{c}659 \\
(\% 56.27) \\
\end{array}$} & \multirow{2}{*}{\multicolumn{3}{|c|}{$\begin{array}{c}216 \\
(\% 18.46)\end{array}$}} \\
\hline & & & & & & \\
\hline
\end{tabular}

Table 5. The Semantic Formulas of Request

\begin{tabular}{|c|c|c|c|c|c|c|c|}
\hline \multirow[b]{2}{*}{ 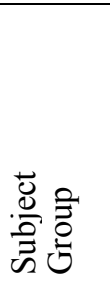 } & \multirow[b]{2}{*}{ 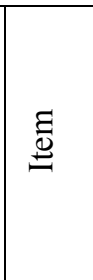 } & \multirow[b]{2}{*}{ 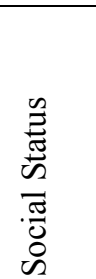 } & \multicolumn{5}{|c|}{ Order of the semantic formulas } \\
\hline & & & 1 & 2 & 3 & 4 & Transfer occurrence \\
\hline \multirow[t]{3}{*}{ INSA } & \multirow{9}{*}{$\# 1$} & \multirow{9}{*}{ 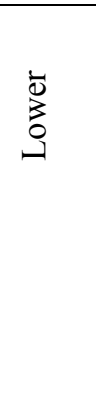 } & Iii & IIiii & (IIvi) & & \multirow{9}{*}{$\begin{array}{l}\text { Instances indicate that a pragmatic } \\
\text { transfer occurs represented by using } \\
\text { similar refusal strategies like } \\
\text { "Reason/Explanation", "Regret", } \\
\text { and "Non-performative statements' } \\
\text { in this speech act. Also, it is } \\
\text { interesting to find out that all the } \\
\text { three groups have the same } \\
\text { tendency in making refusals. The } \\
\text { number of refusal strategies in } \\
\text { requests is less than other situations. }\end{array}$} \\
\hline & & & IIi & IIiii & (IIvi) & & \\
\hline & & & IIiii & IIiv & & & \\
\hline \multirow[t]{3}{*}{ IEFL } & & & $\overline{\mathrm{Iii}}$ & IIIiii & & & \\
\hline & & & IIi & IIiii & & & \\
\hline & & & IIii & IIIx & & & \\
\hline \multirow[t]{3}{*}{ ANSE } & & & Iii & IIIiii & & & \\
\hline & & & III & IIiii & & & \\
\hline & & & IIii & IIix & & & \\
\hline \multirow[t]{3}{*}{ INSA } & \multirow{11}{*}{ \#2 } & \multirow{11}{*}{$\begin{array}{l}\bar{\sigma} \\
\vec{z}\end{array}$} & III & IIiii & & & \multirow{11}{*}{$\begin{array}{l}\text { No instance of pragmatic transfer } \\
\text { occurs represented by using } \\
\text { different refusal strategies. It is } \\
\text { worthy noting that each group } \\
\text { adopts its own tendency, even the } \\
\text { first two groups are about to be } \\
\text { similar. The important point here is } \\
\text { that both IEFL and ANSE use } \\
\text { refusal adjuncts to introduce their } \\
\text { refusing. }\end{array}$} \\
\hline & & & IIIiii & & & & \\
\hline & & & Iii & IIiii & & & \\
\hline \multirow[t]{4}{*}{ IEFL } & & & IIIi & IIIiii & & & \\
\hline & & & Iii & & & & \\
\hline & & & Aiii & IIi & Iii & IIiii & \\
\hline & & & IIii & Iii & & & \\
\hline \multirow[t]{4}{*}{ 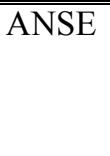 } & & & Iii & IIIiii & & & \\
\hline & & & IIiii & & & & \\
\hline & & & $\mathrm{Ai}$ & IIix & & & \\
\hline & & & Iii & III & IIiii & & \\
\hline \multirow[t]{2}{*}{ INSA } & \multirow{8}{*}{$\# 12$} & \multirow{8}{*}{$\begin{array}{l}\dot{\bar{D}} \\
\bar{D} \\
\dot{D} \bar{I}\end{array}$} & III & Iii & IIiii & & \multirow{8}{*}{$\begin{array}{l}\text { Instances indicate that a pragmatic } \\
\text { transfer occurs since similar refusal } \\
\text { strategies are used.The three groups } \\
\text { use only two or three semantic } \\
\text { formulas due to the interlocutor's } \\
\text { social status. Both IEFL and ANSE } \\
\text { adopt similar refusal strategies, } \\
\text { represented by using non- } \\
\text { performative statement/ regret in the } \\
\text { first position and reason/explanation } \\
\text { in the second or third positions. }\end{array}$} \\
\hline & & & Aiv & IIi & IIiii & & \\
\hline \multirow[t]{3}{*}{ IEFL } & & & Iii & IIiii & & & \\
\hline & & & $\mathrm{IIi}$ & IIiii & & & \\
\hline & & & IIii & IIiii & & & \\
\hline \multirow[t]{3}{*}{ ANSE } & & & III & IIiii & & & \\
\hline & & & Iii & IIIii & IIiii & & \\
\hline & & & IIiii & IIii & IIvi & & \\
\hline
\end{tabular}


Table 6. The Semantic Formulas of Invitation

\begin{tabular}{|c|c|c|c|c|c|c|c|}
\hline \multirow[b]{2}{*}{ 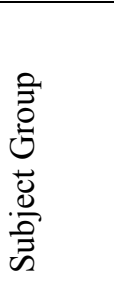 } & \multirow[b]{2}{*}{$\stackrel{\Xi}{\Xi}$} & \multirow[b]{2}{*}{ 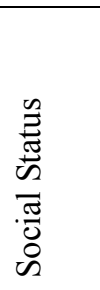 } & \multicolumn{5}{|c|}{ Order of the semantic formulas } \\
\hline & & & 1 & 2 & 3 & 4 & Transfer occurrence \\
\hline \multirow{5}{*}{ INSA } & \multirow{5}{*}{ \#3 } & \multirow[b]{5}{*}{ 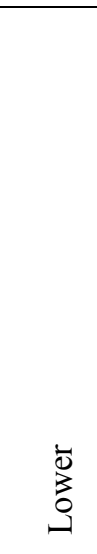 } & Ii & Iii & IIiii & & \multirow{5}{*}{$\begin{array}{l}\text { Instances of a pragmatic } \\
\text { transfer occur. Each group } \\
\text { follows particular patterns } \\
\text { with different types of refusal } \\
\text { adjuncts. Only INSAs and } \\
\text { IEFLs females adopt the } \\
\text { strategy of "Using per- } \\
\text { formative statements' in } \\
\text { refusing invitation of persons } \\
\text { of lower status. IEFL males } \\
\text { and ANSE prefer to use either } \\
\text { the strategy of "Regret" or the } \\
\text { strategy of "Wish" in the first } \\
\text { position followed by different } \\
\text { strategies. }\end{array}$} \\
\hline & & & IIi & IIiii & & & \\
\hline & & & Aiv & IIiii & & & \\
\hline & & & Aiv & Iii & & & \\
\hline & & & Aiv & IIiii & IIvi & & \\
\hline \multirow{6}{*}{ IEFL } & & & III & Iii & IIiii & & \\
\hline & & & Aiii & IIiii & & & \\
\hline & & & IIi & IIiii & & & \\
\hline & & & IIi & IIii & IIV & & \\
\hline & & & Aiv & Iii & IIiii & & \\
\hline & & & IIi & IIV & & & \\
\hline \multirow{4}{*}{ ANSE } & & & IIi & IIiii & Iii & & \\
\hline & & & $\mathrm{Ai}$ & IIvi & & & \\
\hline & & & IIiii & & & & \\
\hline & & & Aiii & IIiii & IIii & & \\
\hline \multirow{4}{*}{ INSA } & \multirow[b]{4}{*}{$\# 4$} & \multirow[b]{4}{*}{ 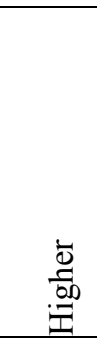 } & Iii & IIiii & & & \multirow{4}{*}{$\begin{array}{l}\text { Iinstances of a pragmatic } \\
\text { transfer occur since different } \\
\text { refusal strategies are used by } \\
\text { INSAs whereas both IEFLs } \\
\text { and ANSEs used "Statement } \\
\text { of regret".Each group follows } \\
\text { particular patterns with } \\
\text { different types of refusal } \\
\text { adjuncts. }\end{array}$} \\
\hline & & & IIi & IIiii & & & \\
\hline & & & IIvi & & & & \\
\hline & & & Aiv & IIiii & & & \\
\hline \multirow{5}{*}{ IEFL } & & & $\overline{\mathrm{Aiv}}$ & IIiii & & & \\
\hline & & & IIi & IIix & IIiii & & \\
\hline & & & IIi & Iii & Aiv & & \\
\hline & & & IIi & IIiii & & & \\
\hline & & & $\mathrm{Ai}$ & IIiii & & & \\
\hline \multirow{5}{*}{ ANSE } & & & $\overline{\mathrm{III}}$ & Iii & IIIiii & & \\
\hline & & & IIi & IIiii & & & \\
\hline & & & Aiv & IIiii & & & \\
\hline & & & Aiv & Iii & & & \\
\hline & & & Aiv & IIiii & IIvi & & \\
\hline \multirow{4}{*}{ INSA } & & & IIii & IIiii & & & \multirow{4}{*}{$\begin{array}{l}\text { Instances of a pragmatic } \\
\text { transfer occur since both } \\
\text { IEFLs and ANSEs used "Non- } \\
\text { performative verbs" and } \\
\text { "Wish". Also, ANSEs used } \\
\text { "Excuse/reason/ explanation". } \\
\text { Each group follows particular } \\
\text { patterns with different types of }\end{array}$} \\
\hline & & & IIi & Iii & IIiii & & \\
\hline & & & Aiv & IIvi & & & \\
\hline & $\# 10$ & $\underset{\text { ت્工 }}{\stackrel{\Xi}{Z}}$ & Aiv & IIiii & & & \\
\hline
\end{tabular}




\begin{tabular}{|c|c|c|c|c|}
\hline & & & & refusal adjuncts \\
\hline \multirow{6}{*}{ IEFL } & Aiv & IIIV & & \\
\hline & Iii & Iii & IIiii & \\
\hline & IIii & Iii & & \\
\hline & IIIi & IIiii & & \\
\hline & Iii & Aiv & IIV & \\
\hline & Iii & & & \\
\hline \multirow{5}{*}{ ANSE } & Aiii & IIiii & IIvi & \\
\hline & Aiv & IIiii & Iii & \\
\hline & Iii & Aiv & IIiii & \\
\hline & III & IIiii & & \\
\hline & III & Iii & IIiii & \\
\hline
\end{tabular}

Table 7. The Semantic Formulas of Suggestion

\begin{tabular}{|c|c|c|c|c|c|c|c|}
\hline \multirow[b]{2}{*}{ 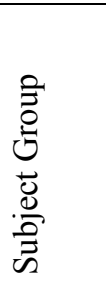 } & \multirow[b]{2}{*}{$\stackrel{\Xi}{\Xi}$} & \multirow[b]{2}{*}{ 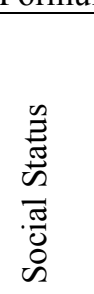 } & \multicolumn{5}{|c|}{ Order of the semantic formulas } \\
\hline & & & 1 & 2 & 3 & 4 & Transfer occurrence \\
\hline \multirow{4}{*}{ INSA } & \multirow{15}{*}{$\# 5$} & \multirow{15}{*}{$\begin{array}{l}\vec{\sigma} \\
\vec{\sigma}\end{array}$} & Iii & IIvii & & & \multirow{15}{*}{$\begin{array}{l}\text { Instances indicate that a } \\
\text { pragmatic transfer occurs in this } \\
\text { speech act since both IEFLs and } \\
\text { ANSEs used similar refusal } \\
\text { strategies like "Excuse/ reason/ } \\
\text { explanation", "Attempt to } \\
\text { dissuade interlocutor" and "Non- } \\
\text { performative verbs". Also, it is } \\
\text { interesting to find out that all the } \\
\text { three groups have the same } \\
\text { tendency in making refusals. } \\
\text { Both IEFL and ANSE use non- } \\
\text { performative statement } \\
\text { (especially I can't) in the first } \\
\text { position and reason in the } \\
\text { second position. In the third and } \\
\text { fourth positions, each adopts its } \\
\text { own tendency of semantic } \\
\text { formulas. }\end{array}$} \\
\hline & & & III & IIV & & & \\
\hline & & & IIvi & & & & \\
\hline & & & Aiv & IIiii & & & \\
\hline \multirow{6}{*}{ IEFL } & & & Aiii & $\begin{array}{l}\text { Iii } \\
\end{array}$ & IIiii & & \\
\hline & & & Aiii & $\mathrm{Ai}$ & Iii & IIiv & \\
\hline & & & Iii & IIiii & & & \\
\hline & & & Aiv & IIiv & IIix & & \\
\hline & & & Iii & Aiv & IIix & & \\
\hline & & & Iii & Aiv & IIiv & & \\
\hline \multirow{5}{*}{ ANSE } & & & Iii & IIviii & & & \\
\hline & & & IIvi & & & & \\
\hline & & & Aiv & IIix & & & \\
\hline & & & IIix & IIiii & IIii & IIIiii & \\
\hline & & & Iii & IIiii & (Aiv) & & \\
\hline \multirow{5}{*}{ INSA } & \multirow{10}{*}{$\# 6$} & \multirow{10}{*}{ 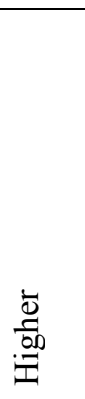 } & IIvii & & & & \multirow{15}{*}{$\begin{array}{l}\text { No instance of a pragmatic } \\
\text { transfer occurs. Each group } \\
\text { follows particular patterns with } \\
\text { different types of refusal } \\
\text { adjuncts. It is worthy noting that } \\
\text { both IEFL and ANSE use refusal } \\
\text { adjuncts (especially gratitude/ } \\
\text { appreciation and pause fillers) in } \\
\text { the first position, followed by } \\
\text { different semantic formulas. }\end{array}$} \\
\hline & & & IIi & IIiii & & & \\
\hline & & & Iii & & & & \\
\hline & & & IIiii & Iii & IIiii & & \\
\hline & & & IIii & Iii & IIiii & & \\
\hline \multirow{5}{*}{ IEFL } & & & Aiv & IIIiii & & & \\
\hline & & & Aiii & Aiv & Iii & & \\
\hline & & & Aiii & Iii & & & \\
\hline & & & IIi & IIvi & & & \\
\hline & & & Aiv & IIvi & III & & \\
\hline \multirow[t]{5}{*}{$\overline{\mathrm{ANSE}}$} & & & 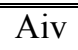 & 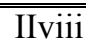 & & & \\
\hline & & & Aiv & IIvi & & & \\
\hline & & & Aiii & IIix & & & \\
\hline & & & $\mathrm{Ai}$ & IIiii & & & \\
\hline & & & $\mathrm{Ai}$ & Iii & IIiii & & \\
\hline \multirow{5}{*}{ INSA } & & \multirow{5}{*}{$\begin{array}{l}\dot{0} \\
\text { ż }\end{array}$} & Iii & IIiii & & & \multirow{5}{*}{$\begin{array}{l}\text { No instance of a pragmatic } \\
\text { transfer occurs . Each group } \\
\text { follows particular patterns with } \\
\text { different types of refusal } \\
\text { adjuncts. IEFL prefer to use non- }\end{array}$} \\
\hline & & & IIvii & & & & \\
\hline & & & III & Iii & & & \\
\hline & & & III & Iii & & & \\
\hline & & & $\begin{array}{l}\text { Aiii } \\
\end{array}$ & IIii & "IIvi & & \\
\hline
\end{tabular}




\begin{tabular}{|c|c|c|c|c|c|c|}
\hline \multirow{4}{*}{ IEFL } & \multirow{10}{*}{$\# 8$} & Iii & IIvi & & & \multirow{10}{*}{$\begin{array}{l}\text { performative statement in the } \\
\text { first position followed by } \\
\text { different formulas. ANSE use } \\
\text { different semantic formulas in } \\
\text { the four positions. }\end{array}$} \\
\hline & & IIi & IIix & & & \\
\hline & & Iii & Iii & IIiii & & \\
\hline & & Iii & & & & \\
\hline \multirow{6}{*}{ ANSE } & & IIviii & & & & \\
\hline & & IIvii & & & & \\
\hline & & Aiv & IIvi & & & \\
\hline & & Aiii & IIix & IIvii & Iii & \\
\hline & & IIvii & IIviii & & & \\
\hline & & Iii & IIvii & IIvi & & \\
\hline
\end{tabular}

Table 8. The Semantic Formulas of Offer

\begin{tabular}{|c|c|c|c|c|c|c|c|}
\hline \multirow[b]{2}{*}{ 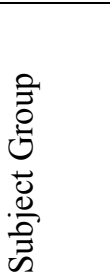 } & \multirow[b]{2}{*}{ Еี } & \multirow[b]{2}{*}{ 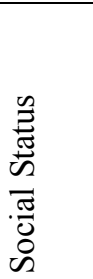 } & \multicolumn{5}{|c|}{ Order of the semantic formulas } \\
\hline & & & 1 & 2 & 3 & 4 & Transfer occurrence \\
\hline \multirow{5}{*}{ INSA } & \multirow{15}{*}{ \#7 } & \multirow{15}{*}{$\begin{array}{l}\dot{\Phi} \\
\vdots \\
0 \\
0\end{array}$} & Iii & IIiii & & & \multirow{15}{*}{$\begin{array}{l}\text { Instances indicate that a } \\
\text { pragmatic transfer occurs } \\
\text { in this speech act. Also, it } \\
\text { is interesting to find out } \\
\text { that all the three groups } \\
\text { have the same tendency in } \\
\text { making refusals. } \\
\text { Both IEFL and ANSE use } \\
\text { refusal adjuncts (even of } \\
\text { different types) or non- } \\
\text { performative statement in } \\
\text { the first position and } \\
\text { reason/ explanation in the } \\
\text { second or third positions. }\end{array}$} \\
\hline & & & IIii & Iliii & & & \\
\hline & & & Ii & & & & \\
\hline & & & Aiv & Ii & IIiii & & \\
\hline & & & III & IIiii & & & \\
\hline \multirow{5}{*}{ IEFL } & & & Iii & $\overline{\text { IIIx }}$ & & & \\
\hline & & & Aiii & IIix & IIix & & \\
\hline & & & Iii & Iliv & & & \\
\hline & & & Iii & Iii & IIix & & \\
\hline & & & IIv & & & & \\
\hline \multirow{5}{*}{ ANSE } & & & $\mathrm{Ai}$ & Iii & Iliii & & \\
\hline & & & Avoidance & & & & \\
\hline & & & Aiii & IIIx & IIviii & & \\
\hline & & & IIix & & & & \\
\hline & & & IIviii & IIix & & & \\
\hline \multirow[t]{4}{*}{ INSA } & \multirow{15}{*}{ \#9 } & \multirow{15}{*}{ 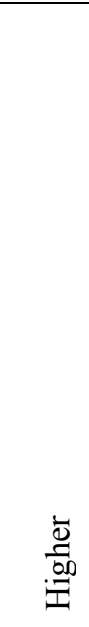 } & IIi & IIiii & & & \multirow{15}{*}{$\begin{array}{l}\text { Instances indicate that a } \\
\text { pragmatic transfer occurs } \\
\text { in this speech act. Also, it } \\
\text { is interesting to find out } \\
\text { that all the three groups } \\
\text { have the same tendency in } \\
\text { making refusals. IEFL } \\
\text { females make more use of } \\
\text { "I refuse." than males, and } \\
\text { all reasons are related to } \\
\text { family business. }\end{array}$} \\
\hline & & & Iii & Ii & & & \\
\hline & & & Aiv & Iii & Iliii & & \\
\hline & & & Aiv & Iii & & & \\
\hline \multirow[t]{6}{*}{$\overline{\text { IEFL }}$} & & & IIIii & Iii & & & \\
\hline & & & Iii & Aiv & Iliii & & \\
\hline & & & Iliii & & & & \\
\hline & & & Aiv & Iii & & & \\
\hline & & & Aiv & Iii & IIiv & & \\
\hline & & & Aiv & IIiii & Iii & IIvii & \\
\hline \multirow[t]{5}{*}{ ANSE } & & & Iii & Aiv & IIiii & & \\
\hline & & & Aiii & $\overline{\mathrm{Ai}}$ & IIiv & & \\
\hline & & & Iii & $\mathrm{Ai}$ & IIiii & & \\
\hline & & & IIii & & & & \\
\hline & & & IIii & $\mathrm{Ai}$ & Aiv & & \\
\hline \multirow[t]{5}{*}{ INSA } & \multirow{10}{*}{$\# 11$} & \multirow{10}{*}{ 氶 } & Aiv & IIiii & & & \multirow{10}{*}{$\begin{array}{l}\text { Instances indicate that a } \\
\text { pragmatic transfer occurs } \\
\text { in this speech act. Also, it } \\
\text { is interesting to find out } \\
\text { that all the three groups } \\
\text { have the same tendency in } \\
\text { making refusals. Both } \\
\text { IEFL and ANSE use non- } \\
\text { performative in the first } \\
\text { position and reason/ } \\
\text { explanation in the second }\end{array}$} \\
\hline & & & IIi & IIiii & IIviii & & \\
\hline & & & Aiv & Ii & Iii & & \\
\hline & & & Aiv & IIiii & & & \\
\hline & & & $\mathrm{Ii}$ & Iii & & & \\
\hline \multirow[t]{5}{*}{$\overline{I E F L}$} & & & $\overline{\mathrm{Ii}}$ & IIIi & IIIiii & & \\
\hline & & & Iii & Aiv & IIiii & & \\
\hline & & & $\mathrm{Ai}$ & IIiv & & & \\
\hline & & & Ii & Iliv & & & \\
\hline & & & Iii & IIv & Aiv & & \\
\hline
\end{tabular}




\begin{tabular}{|c|c|c|c|c|c|}
\hline \multirow{3}{*}{$\overline{\text { ANSE }}$} & Aiv & Iii & IIiii & & \multirow{7}{*}{$\begin{array}{l}\text { or third positions. The } \\
\text { second position } \\
\text { sometimes filled with } \\
\text { refusal adjuncts. }\end{array}$} \\
\hline & Aiv & IIiii & & & \\
\hline & $\overline{\mathrm{Ai}}$ & IIIiii & $\overline{\mathrm{IIV}}$ & & \\
\hline & IIiii & Aiv & IIvi & & \\
\hline & Aiv & Iii & IIiii & & \\
\hline & IIviii & & & & \\
\hline & Iii & Aiv & IIiii & (IIiii) & \\
\hline
\end{tabular}

Table 9. The Use of Refusal Adjuncts: A Comparison

\begin{tabular}{|c|c|c|c|c|c|}
\hline No & Speech Acts & Items & INSA & IEFL & ANSE \\
\hline \multirow{3}{*}{1} & \multirow{3}{*}{ Request } & $\# 1$ & 8 & 8 & 2 \\
\hline & & \#2 & 4 & 4 & 2 \\
\hline & & $\# 12$ & 9 & 9 & 3 \\
\hline \multirow{3}{*}{2} & \multirow{3}{*}{ Invitation } & $\# 3$ & 12 & 12 & 13 \\
\hline & & $\# 4$ & 19 & 19 & 12 \\
\hline & & $\# 10$ & 13 & 13 & 6 \\
\hline \multirow{3}{*}{3} & \multirow{3}{*}{ Suggestion } & $\# 5$ & 16 & 16 & 5 \\
\hline & & \#6 & 23 & 23 & 10 \\
\hline & & $\# 8$ & 8 & 8 & 4 \\
\hline \multirow{3}{*}{4} & \multirow{3}{*}{ Offer } & \#7 & 8 & 7 & 7 \\
\hline & & \#9 & 23 & 23 & 10 \\
\hline & & \#11 & 27 & 27 & 8 \\
\hline \multicolumn{3}{|c|}{ Total } & 170 & 169 & 82 \\
\hline \multicolumn{3}{|c|}{$\%$} & 40.38 & 40.14 & 19.48 \\
\hline \multicolumn{3}{|c|}{ Total } & & 421 & \\
\hline
\end{tabular}

Table 10. Male and Female IEFL: Use of Refusal Adjuncts

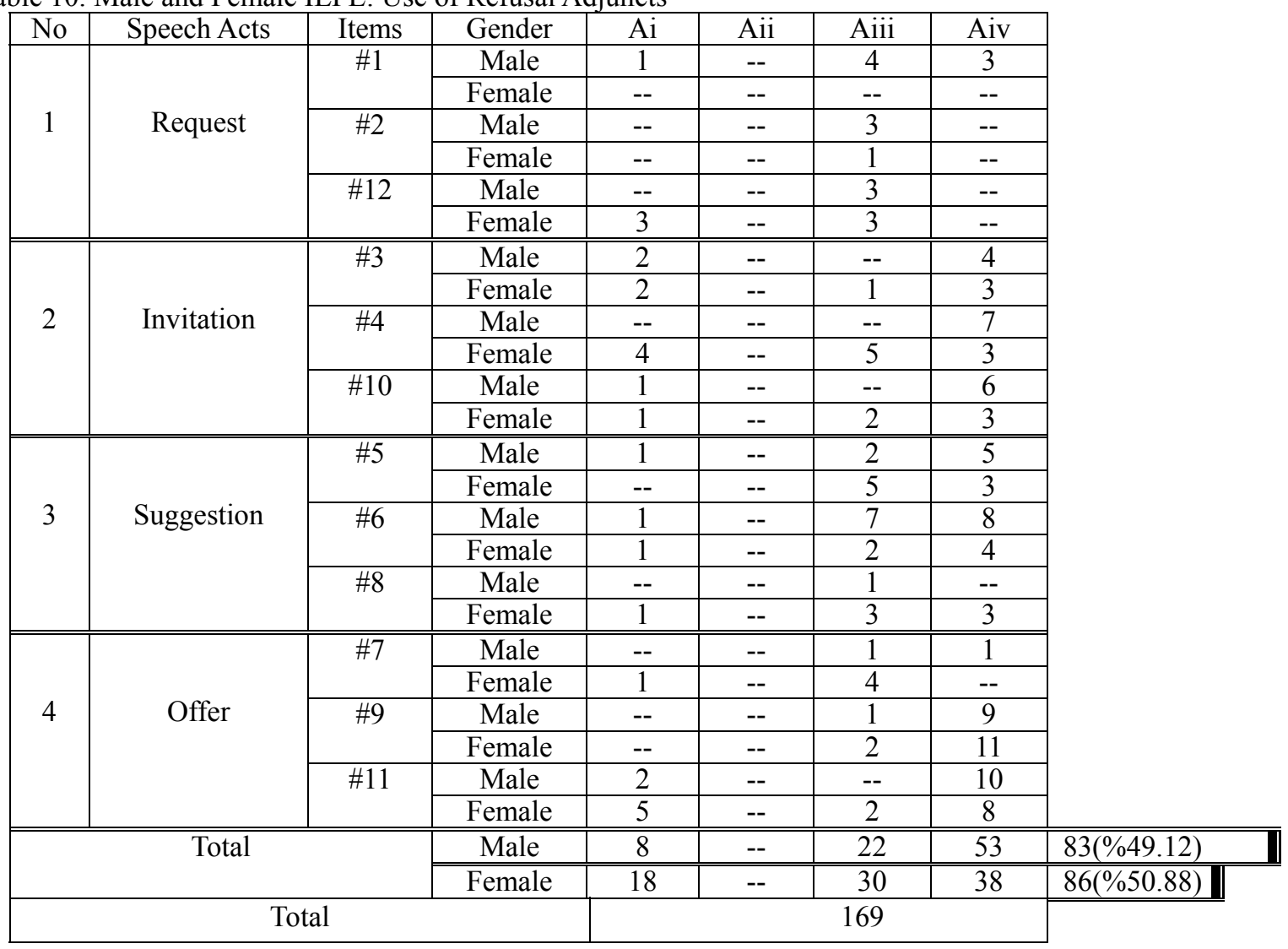


Table 11. Interlocutors' Social Status: A Comparison

\begin{tabular}{|c|c|c|c|c|c|c|c|c|c|}
\hline \multirow[b]{2}{*}{ ż } & \multirow{2}{*}{$\begin{array}{l}\text { ड̃ } \\
\mathbb{E} \\
\text { है } \\
\text { की }\end{array}$} & \multirow[b]{2}{*}{ 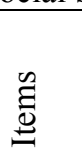 } & \multirow{2}{*}{$\begin{array}{l}\text { Social } \\
\text { Status }\end{array}$} & \multicolumn{2}{|c|}{ INSA } & \multicolumn{2}{|c|}{ IEFL } & \multicolumn{2}{|c|}{ ANSE } \\
\hline & & & & No & $\%$ & No & $\%$ & No & $\%$ \\
\hline \multirow[t]{3}{*}{1} & \multirow{3}{*}{$\overrightarrow{\vec{g}_{0}}$} & $\# 1$ & Lower & 27 & 9.14 & 67 & 10.18 & 24 & 11.16 \\
\hline & & $\# 2$ & Equal & 24 & 8.10 & 69 & 10.50 & 20 & 9.25 \\
\hline & & $\# 12$ & Higher & 27 & 9.14 & 63 & 9.55 & 20 & 9.25 \\
\hline \multirow[t]{3}{*}{2} & \multirow{3}{*}{ 蛋. 总 } & $\# 3$ & Lower & 25 & 8.44 & 55 & 8.34 & 17 & 7.87 \\
\hline & & $\# 4$ & Higher & 27 & 9.14 & 58 & 8.80 & 18 & 8.33 \\
\hline & & $\# 10$ & Equal & 26 & 8.78 & 61 & 9.25 & 19 & 8.79 \\
\hline \multirow[t]{3}{*}{3} & \multirow{3}{*}{ 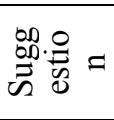 } & $\# 5$ & Equal & 24 & 8.10 & 47 & 7.13 & 16 & 7.40 \\
\hline & & $\# 6$ & Higher & 24 & 8.10 & 47 & 7.13 & 14 & 6.48 \\
\hline & & $\# 8$ & Lower & 26 & 8.78 & 53 & 8.04 & 17 & 7.87 \\
\hline \multirow[t]{3}{*}{4} & \multirow{3}{*}{$\mathbb{E}_{0}^{0}$} & $\# 7$ & Lower & 22 & 7.43 & 44 & 6.67 & 18 & 8.33 \\
\hline & & $\# 9$ & Equal & 24 & 8.10 & 48 & 7.28 & 14 & 6.48 \\
\hline & & $\# 11$ & Higher & 20 & 6.75 & 47 & 7.13 & 19 & 8.79 \\
\hline & & \multirow{2}{*}{\multicolumn{2}{|c|}{ Total }} & 296 & 25.27 & 659 & 56.27 & 216 & 18.44 \\
\hline & & & & \multicolumn{6}{|c|}{1171} \\
\hline
\end{tabular}

Table 12. Male and Female IEFL Performance and Social status

\begin{tabular}{|c|c|c|c|c|c|c|c|}
\hline No & Speech Acts & Items & $\begin{array}{l}\text { Social } \\
\text { status }\end{array}$ & Male & $\%$ & Female & $\%$ \\
\hline \multirow{3}{*}{1} & \multirow{3}{*}{ Request } & $\# 1$ & Lower & 33 & 9.40 & 34 & 11.03 \\
\hline & & $\# 2$ & Equal & 38 & 10.82 & 31 & 10.06 \\
\hline & & $\# 12$ & Higher & 32 & 9.11 & 31 & 10.06 \\
\hline \multirow{3}{*}{2} & \multirow{3}{*}{ Invitation } & \#3 & Lower & 29 & 8.29 & 26 & 8.44 \\
\hline & & $\# 4$ & Higher & 32 & 9.11 & 26 & 8.44 \\
\hline & & $\# 10$ & Equal & 29 & 8.29 & 32 & 10.46 \\
\hline \multirow{3}{*}{3} & \multirow{3}{*}{ Suggestion } & $\# 5$ & Equal & 28 & 7.97 & 19 & 6.16 \\
\hline & & $\# 6$ & Higher & 22 & 6.26 & 25 & 8.11 \\
\hline & & $\# 8$ & Lower & 32 & 9.11 & 21 & 6.81 \\
\hline \multirow{3}{*}{4} & \multirow{3}{*}{ Offer } & $\# 7$ & Lower & 23 & 6.55 & 21 & 6.81 \\
\hline & & $\# 9$ & Equal & 27 & 7.69 & 21 & 6.81 \\
\hline & & $\# 11$ & Higher & 26 & 7.40 & 21 & 6.81 \\
\hline & Total & & & 351 & 53.91 & 308 & 46.09 \\
\hline & Total & & & & 659 & & \\
\hline
\end{tabular}

\section{Appendix}

Discourse Completion Test

Directions: Please read the following situation and then complete them by refusing. Do not spend a lot of time thinking about what answer you think you should provide; instead, please respond as naturally as possible and try to write your response as you feel you would say it in the situation.

1. You are the owner of a bookstore. One of your best workers asks to speak to you in private. The worker says, "I know that this will be a busy week-end at the store, but it's my mother's birthday and we have planned a big family get together. I'd like to take the week-end off." (Request: Person of lower status makes the request).

You:-------------------------------------------

2. You are in your third year of college. You attend classes and you take really good notes. Your classmate often misses a class and asks you for the lecture notes. On this occasion, your classmate says, "Oh no! We have an exam tomorrow but I don't have the notes from last week. I am sorry to ask you this, but could you please lend me your notes once again?" (Request: Equal status).

You:-

3. You are the president of a printing company. A salesman from a company that sells paper invites you to an expensive dinner. The salesman says, "We have met several times to discuss your purchase of my company's products. I was wondering if you would like to be my guest at the (name of expensive restaurant) in order to firm 
up the contract." (Invitation: Person of lower status makes the invitation).

You:-

4. You are a top executive at a very large accounting firm. One day, the boss calls you into his office. He says, "Next Sunday my wife and I are having a little party. I know it's short notice, but I'm hoping that all of my top executives will be there with their spouses. What do you say?" (Invitation: Person of higher status makes the invitation).

You:-

5. You are at a friend's house watching TV. The friend offers you a snack. You turn it down, saying that you have gained some weight and don't feel comfortable in your new clothes. Your friend says, “Hey, why don't you try this new diet I've been telling you about?" (Suggestion: Equal Status).

You:-

6. You are at your desk trying to find a report that your boss just asked for. While you are searching through the mess on your desk, your boss walks over and says, "You know, maybe you should try and organize yourself better. I always write myself little notes to remind me of things. Perhaps you should give it a try." (Suggestion: Person of higher status makes the suggestion).

You:-

7. You arrive home and notice that your cleaning lady is extremely upset. She comes rushing up to you and says, "'Oh God, I'm so sorry! I had an awful accident. While I was cleaning I bumped into the tables and your china vase fell and broke. I just feel terrible about it.I'm ready to pay for" (Offer: Person of lower status makes the offer).

You:-

8. You are a teacher at a university. It is just about the middle of the term now and one of your students asks to speak to you. The student says, "Ah, excuse me. Some of the students were talking after class recently and we kind of feel that you lecture a lot in class. Could you give us more application or case studies in class?" (Suggestion: Person of lower status makes the suggestion).

You:-

9. You are at a friend's house for lunch. Your friend says, “How about another piece of cake?" (Offer: Equal status).

You:-

10. A friend invites you to dinner, but you really cannot stand this friend's fiance. Your friend says, "How about coming over for dinner Saturday night? We're having a small dinner party." (Invitation: Equal Status).

You:-

11. You have been working in an advertising agency now for some time. The boss offers you a raise and a promotion, but it involves moving. You do not want to go. Today, the boss calls you into his office. He says, "I'd like to offer you an executive position in our new offices in (name of smaller town). It's a great town only three hours from here by plane. And, a nice raise comes with the position." (Offer: Person of higher status makes the offer).

You:-

12. You are at the office in a meeting with your boss. It is getting close to the end of the day and you want to leave work. But your boss says, "If you don't mind, I'd like you to spend an extra hour or two tonight so that we can finish this." (Request: Person of higher status)

You: 